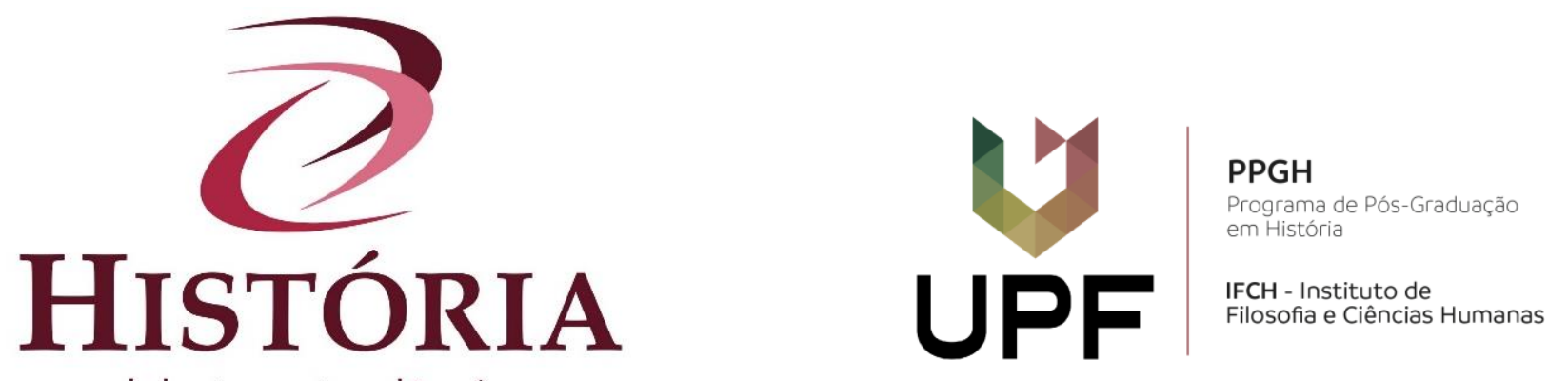

debates e tendências

\title{
Migração e biografia: aspectos históricos de um relacionamento emocionante *
}

\author{
Migration and biography: historical aspects of an exciting relationship
}

Migración y biografía: aspectos históricos de una relación emocionante

Peter Alheit ${ }^{\mathrm{i}}$

\begin{abstract}
Resumo: O artigo a seguir 'Migração e Biografia: aspectos históricos de um relacionamento emocionante' trata do tema da complexa relação entre (auto)biografia e migração. Trata-se de uma abordagem sobre a sensibilidade para transformações formativas dessa relação. Exemplos do "pré-moderno", da "modernidade clássica", da chamada "modernidade organizada" (Reckwitz) e do "pós-modernismo" mostram que tanto o caráter das migrações quanto as disposições subjetivas dos atores afetados por elas podem mudar.

Palavras-chave: Migração. (Auto)biografia. Pré-moderno/modernidade clássica/modernidade organizada/pós-modernidade. Migrações transnacionais e conhecimento biográfico transnacional.
\end{abstract}

Abstract: The following article 'Migration and biography: historical aspects of an exciting relationship' addresses the complex relationship between (auto)biography and migration. It is an approach on sensitivity to formative transformations of this relationship. Examples of "premodern", "classical modern", so-called "organized modernity" (Reckwitz) and "postmodernism" show that both the character of the migrations and the subjective dispositions of the actors affected by them can change.

Keywords: Migration. (Auto)biography. Pre-modern/classical modern/organized modernity/post-modernity. Transnational migration and transnational biographical knowledge.

Resumen: El siguiente artículo "Migración y biografía: aspectos históricos de una relación emocionante" trata del tema de la compleja relación entre (auto) biografía y migración. Se trata de un enfoque sobre la sensibilidad a las transformaciones formativas de esta relación. Los ejemplos del "pre-moderno", de la "modernidad clásica", de la llamada "modernidad organizada" (Reckwitz) y del "posmodernismo" demuestran que tanto el carácter de las migraciones como las disposiciones subjetivas de los actores afectados por ellas pueden cambiar.

Palavras-clave: La migración. (Auto)biografia. Premoderno/modernidad clásica/modernidad organizada/posmodernidad. Migraciones transnacionales y conocimiento biográfico transnacional. 


\section{Introdução}

As seguintes considerações tratam de uma visão histórica da relação de migração e biografia. Sem dúvida, desde o início da pesquisa sobre migração sistemática na Escola de Sociologia de Chicago - Chicago School of Sociology (THOMAS; ZNANIECKI, 1958), o conceito de biografia tornou-se uma ferramenta central de pesquisa, uma referência válida até os mais recentes debates em pesquisa migratória. No entanto, esse fato obscurece a visão das mudanças históricas na relação entre migração e biografia. No decorrer da modernidade, os problemas e o foco mudaram. Isso pode se tornar mais transparente em quatro limiares exemplificativos de tempo:

- uma breve lembrança histórica da conexão entre a migração e a (auto)biografia nos tempos pré-modernos;

- uma reflexão sobre o perfil especial dos grandes movimentos migratórios (no chamado "novo mundo") do século XVII ao século XIX, ou seja: sobre o perfil migratório da modernidade clássica;

- nas migrações trabalhistas claramente diferenciadas, especialmente na Europa do século XX, ocasionalmente descrita como um sintoma de modernidade organizada (RECKWITZ, 2006, p. 336s.);

- finalmente, o fenômeno das "migrações transnacionais", que está emergindo mundialmente na transição para o século XXI, ou seja, no pós-modernismo, e que altera padrões migratórios, bem como formatos biográficos e códigos temáticos (APITZSCH, 2014; SIOUTI, 2018).

\section{Migração e (auto)biografia no limiar do moderno}

Os formatos (auto)biográficos da pré-modernidade têm inicialmente muito pouco a ver com a descrição da singularidade individual, como será típico das (auto)biografias modernas (ALHEIT, 2014; ALHEIT; BRANDT, 2006). São representações de reis e de santos, de heróis e de eleitos. Também não é sobre autenticidade ou realidade confiável. A apresentação de tais trabalhos é motivada “didaticamente" (ALHEIT, 2019a). Ela quer entreter os leitores e ensinar-lhes alguma coisa.

No entanto, se procurarmos exemplos que provem o motivo da particularidade e distinção mesmo antes da modernidade clássica, a relação com o motivo da migração 
torna-se imediatamente aparente. O mais antigo exemplo sobre isso, sem dúvida a primeira verdadeira autobiografia da história mundial, são as Confissões (AGUSTINUS, 1888), obra publicada no ano de 399, de autoria de Santo Agostinho de Hipona (354430), nascido em Tagaste. Sua maneira de falar com Deus, de abordar um eu e um você é altamente moderna (BRACHTENDORF, 2005). Mas a chance de encontrar esse $e u$ tem a ver com as experiências de migração do norte da África para Roma e Milão, com uma consequente conversão ao cristianismo (oitavo livro das Confissões) e um retorno final à Numídia como bispo de Hipona (AGUSTINUS, 1888) ${ }^{\text {ii }}$. A experiência de uma vida em movimento, o encontro forçado ou mesmo encenado com mundos sociais sempre novos, a necessidade de mudar perspectivas, cria a condição básica para a narração de uma história de vida quase moderna.

Formatos comparáveis podem ser encontrados no período pré-moderno apenas muitos séculos depois - como a mística Hildegard von Bingen (1098-1179). Também no seu caso, o motivo é a mudança vitalícia de localização e de viagem, isto é, a consciente e, em parte, encenada experiência de migração, um pré-requisito importante para a percepção de sua singularidade individual no encontro místico com Deus (HELECK, 1998). Dois séculos depois, no início do Renascimento italiano é impressionante que artistas, atores e malabaristas realizem suas autobiografias em palcos, mas também as escrevam (BURKE, 1987; BATTISTINI, 2016). A consciência de sua própria particularidade surge aqui não apenas pela profissionalidade exposta, que foi ocasionalmente associada a experiências de exclusão e de abuso. Este fato é gerado principalmente pela viagem necessária de um lugar para outro, pela apresentação de sua própria arte em locais sempre novos - ou seja, por forçada migração interna.

A descoberta pré-moderna da própria individualidade está, portanto, quase sempre associada à experiência muito intensa de ser singular e estranho e não pertencer a ela (ALHEIT, 2014). Essa percepção, característica dos processos de migração, parece ser o pré-requisito decisivo para a consciência biográfica.

Sobre esse tipo de auto experiência e auto expressão, a primeira autobiografia de um membro da classe média baixa, escrita em alemão, é um documento interessante: a história da vida de Ulrich Bräker, o Homem pobre em Tockenburg, como o autor se autodenomina no título ([1789] 1997). Bräker nasceu no leste da Suíça em 1735 e cresceu num ambiente de agricultura familiar. A religiosidade pietista da família garantiu sua alfabetização. Um recrutamento não planejado para o exército prussiano está associado a experiências de choque biográfico e provoca uma relação reflexiva duradoura com sua 
biografia. No entanto, Bräker ainda não encontra expressão literária para sua biografia. Em certo sentido, a autobiografia se divide em duas partes: - uma descrição impressionante do desenvolvimento da criança antes do recrutamento; e, - uma cadeia de reflexão fragmentária e vagamente literária sobre o período após o retorno do serviço militar (ALHEIT; SCHÖMER, 2009). Característica é a laboriosa, sempre repetida e no final falida tentativa de criar uma espécie de coerência quanto a sua vida. A autobiografia permanece um fragmento, como se fosse a crônica de um não-idêntico. Ele mostra a consciência biográfica completamente quebrada de subclasses sociais no limiar da modernidade, mas também prova o ímpeto de autorreflexão através de uma experiência migratória particularmente insistente, o recrutamento involuntário para o exército prussiano (ALHEIT, 2019b). Biografia e migração são irmãs históricas. Uma se move e encena a outra.

\section{0 perfil migratório da modernidade clássica}

Essa reflexão nos sensibiliza para a consideração mais sistemática das migrações clássicas do mundo ocidental no início da modernidade, em particular os movimentos de emigração para a América do Norte que começaram no século XVII e duraram até o século XIX. No modelo push-and-pull da migração de Everett S. Lee (1966), são os primeiros motivos de emigração - push (impulso) - que permitem que pessoas da Europa migrem para as novas áreas de expansão territorial dos EUA: - as consequências dramáticas da Guerra dos Trinta Anos (1618-1648), que afetam particularmente os pequenos Estados alemães (MÜNKLER, 2017); mas, também, guerras religiosas, por exemplo, na Inglaterra do século XVII, que forçam os praticantes puritanos e presbiterianos a partir para a América (EVANS, 2017), provam a pressão ("Push-Motiv" - impulso motivacional) que torna a decisão de migração inevitável.

Com as experiências das primeiras gerações de emigrantes, que em parte estão registradas em cartas (BADE et al., 2007), a importância do Pull-Motive - dos motivos de atração -, isto é, a atração da ideia de migração, aumenta consequentemente. O país da liberdade religiosa, a América (Estados Unidos da América do Norte), é muitas vezes estilizado como a Jerusalém Celestial (STEFFENSKY, 2005). As pessoas, especialmente os virtuosos religiosos da Velha Europa, são atraídas.

E, no entanto, testemunhos autobiográficos ainda são raros - escondidos no início de diários ou em cartas preservadas. É importante perceber que fenômenos como 
identidade pessoal ou autonomia individual, além da alfabetização não obrigatória, requisitos fundamentais para escrever uma autobiografia, podem ser registrados, na melhor das hipóteses, associados com uma elite educacional limitada. O ímpeto para a reflexão da própria vida é dado no Novo Mundo (ALHEIT; DAUSIEN, 1990). Uma tradição (auto)biográfica surge muito depois.

Para entender como é recente a ideia de uma vida longa, uma comparação estatística informativa das taxas de mortalidade da sociedade dos EUA, entre 1840 e 1980, pretende substanciar a consciência biográfica disseminada da ainda jovem população imigrante da América do Norte:

Gráfico 1 - Taxas de mortalidade da sociedade norte-americana

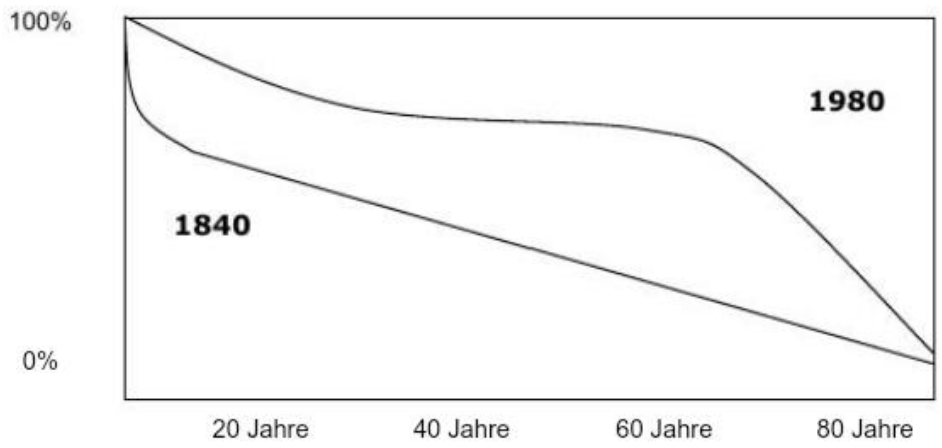

Fonte: FRIES; CRAPO, 1981.

Podemos imaginar como as pessoas com a curva de mortalidade coletiva de 1840 se sentem em seu mundo. Após a experiência generalizada de que a taxa de mortalidade de bebês ainda é relativamente alta, a expectativa de fases subsequentes da vida parece não dramática. A curva de mortalidade corre quase na diagonal através das idades. No entanto, o que isso significa em termos concretos? A taxa de mortalidade para cada indivíduo em todas as fases da vida é de cerca de 50\%. Então as pessoas têm uma disposição básica para a vida, como expressa no belo hino do século XVI: "Mitten wir im Leben sind von dem Tod umfangen" ["No meio da vida estamos cercados pela morte"]. Eles podem pertencer a uma comunidade da aldeia, que visita a igreja todos os domingos. Eles se sentem confortados e nas mãos de Deus, embora tenham que experimentar diariamente que os membros da comunidade - e não apenas os idosos - são arrancados de suas vidas por doenças ou acidentes. No entanto, esta situação não permite um plano de vida individual, como é característico da vida de nossos dias. A atitude para com a vida ainda é pré-moderna (ALHEIT, 2014). E o tempo em que essa condição era normal para a grande maioria das pessoas não chega a 200 anos atrás. 
Em 1980, a situação parece completamente diferente: estatisticamente há muito baixo risco de mortalidade no nascimento e uma alta expectativa de vida é muito provável. O limite de idade previsto tem excedido os 70 anos. Um jovem de 15 ou 18 anos pode facilmente passar para outros 60 anos com confiança. Em tal sociedade, o planejamento da vida se tornou uma questão fundamental, porque a longa vida (IMHOF, 1988) é um fenômeno de massa. O significado reconfortante das religiões diminuiu sensivelmente.

O que a grande maioria da população dos EUA ainda não tem no século XIX é, naturalmente, uma longa vida. No entanto, esse é precisamente o pré-requisito para a consciência autobiográfica (ALHEIT; BRANDT, 2006). A ligação entre migração e biografia parece depender de bem mais do que a simples experiência de uma mudança de local, embora o caminho da Europa para o Novo Mundo tenha, sem dúvida, libertado o potencial de reflexão e educação de muitos protagonistas.

Talvez seja interessante mudar a perspectiva e focar na observação da migração para o Brasil:

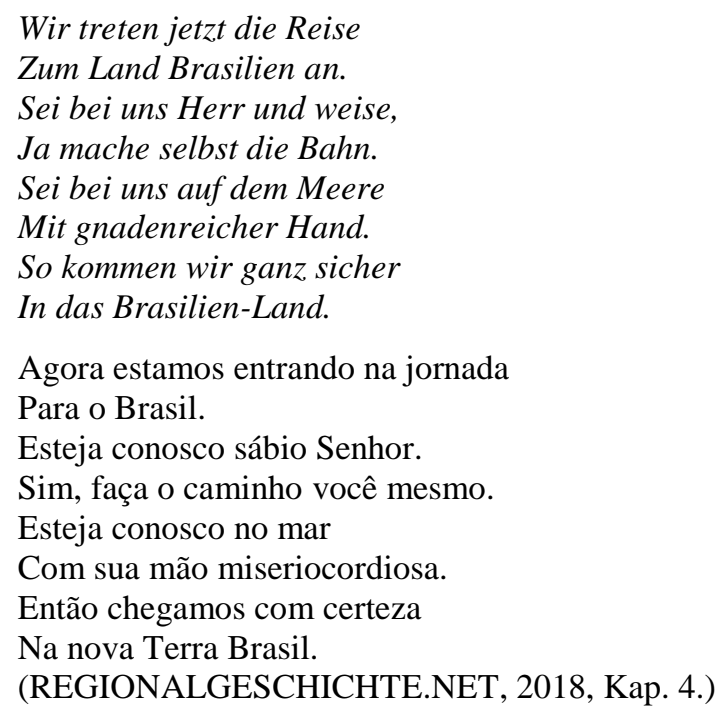

Esta é a primeira estrofe da chamada Brasilien Liedes [Canção do Brasil], com a qual os migrantes das aldeias do Hunsrück, no sudoeste da Alemanha, se despediram de sua terra natal. A canção demostra grande esperança ("Durch Gott sind wir berufen..." [Por Deus, somos chamados...], "Die Freudentränen fließen... [As lágrimas da alegria fluem...], "Willkommen spricht der Kaiser... [Bem-vindo, diz o Imperador...]) e mostra no modelo de Everett S. Lee (1966) - que os Pull Motivos parecem dominar fatores de impulso.

Se seguirmos os migrantes de Hunsrück para São Leopoldo (Rio Grande do Sul, Brasil), onde a primeira colônia alemã foi fundada em 25 de julho de 1824, no chamado "Dia dos Colonos", o tom brilhante da música brasileira diminui um pouco. Um 
testemunho autobiográfico, uma carta que Michael Burkhard, de Kirchberg, escreveu para sua terra natal em 3 de novembro de 1827, fala sobre a dura realidade enfrentada e a clara decepção:

Meine lieben Brüder und Freunde!

Ich bin glücklich, endlich nach einer Reise von 18 Wochen hierher gekommen, zwar habe ich mir mehrmals auf der See den Tod als wie das Leben gewünscht; denn obgleich mir der Himmel sehr gnädig war, und meine Familie verschont hat, so sind doch 48 Personen auf der See umgekommen ... [Es] fällt mir hier beständig das Sprichwort ein: bleibe im Lande und nähre dich redlich, und hätte ich es noch einmal zu thun, so würde ich nicht mehr fortreisen... Was man nach Deutschland so schönes aus diesem Land geschrieben hat, sind lauter Lügen ...

(REGIONALGESCHICHTE.NET, 2018, Kap. 5.).

Meus queridos irmãos e amigos!

Estou feliz por finalmente chegar aqui depois de uma jornada de 18 semanas, embora eu tenha repetidamente desejado a morte no mar como desejado a vida; porque embora o céu tenha sido muito gentil comigo e poupado minha família, 48 pessoas pereceram no mar... [Isso] me lembra constantemente o ditado: fique no país e se alimente honestamente, e se eu tivesse que fazer isso de novo, assim, eu não iria sair... O que de tão belo escreveram para a Alemanha, sobre este país, são todas mentiras...

(REGIONALGESCHICHTE.NET, 2018, Kap. 5.).

Se avaliarmos de forma mais sistemática os poucos testemunhos autobiográficos disponíveis a partir desse período, devemos concluir que: - especialmente quanto as migrações para o Brasil, não se tratam de experiências individuais, mas de experiências de migração coletiva. Que são realizadas em coletivos religiosos ou de parentesco, pelo menos em unidades familiares, e formam na migração - como na colônia - uma nova coesão coletiva.

Como os motivos iniciais - Pull-Motive - de atração costumam ser frustrados, e os desafios do país exigem compromisso pessoal e energia extremos, a necessidade de assimilação na nova sociedade é muito menor do que a necessidade de se manter unidos e se diferenciar. Isso muitas vezes leva a cultura e a língua de origem a sobreviver por mais tempo e de forma mais sustentável do que em movimentos migratórios recentes (REGIONALGESCHICHTE.NET, 2018, Kap. 8.). A hermetização das subculturas religiosas pertence a esse contexto. Exemplos não são apenas os Amish na América do Norte, mas também o Mucker em torno de Jacobina Maurer, perto de São Leopoldo (DICKIE, 2018).

Para resumir estes breves exemplos, deve ser determinado: - as migrações clássicas da Europa para as Américas do Norte e do Sul, que acontecem entre o final do século XVII e o século XIX, são - além de destinos individuais - migrações em alianças coletivas. Na melhor das hipóteses, documentos autobiográficos podem ser encontrados em diários de viagem e em cartas. Conceitos de uma "Identität für sich" [identidade para si mesmo] (HAHN, 1988), como pressuposto da consciência autobiográfica, são apenas 
parcialmente desenvolvidos e auto evidentes entre as elites educacionais. A relação entre (auto)biografia e migração não é um automatismo. Baseia-se no desenvolvimento gradual da subjetividade moderna (ALHEIT, 2019a; 2019b), em que as experiências de migração são, sem dúvida, de importância central.

\section{Migrações trabalhistas na modernidade organizada}

Isto toca o limiar do terceiro tempo e seu tema, as migrações trabalhistas, vinculadas as necessidades de trabalho, do século XX. Este problema de pesquisa está ligado ao estudo da migração, que, ao mesmo tempo, representa o trabalho fundamental da pesquisa biográfica em ciências sociais: a obra "The Polish Peasant in Europe and America", publicada em sua primeira edição em 1918-1920 por William Isaac Thomas e Florian Znaniecki (1958). A autobiografia do agricultor polonês Władysław Wiśniewski documenta duas coisas, a saber: - que, entre os protagonistas os recursos da cultura polonesa na sociedade dos EUA são mais sustentáveis do que a política de imigração do Estado Americano; - mas, também mostra que a identidade profissional e cultural do autobiógrafo é transformada e tornada mais clara na experiência da migração (THOMAS; ZNANIECKI, 1958; SIOUTI, 2018). O mundo no qual Władysław ingressa também é um novo mundo, em que o trabalho industrial substitui a vida camponesa. E essa substituição marca também um novo estágio de desenvolvimento da modernidade, a Modernidade Organizada ${ }^{\mathrm{iii}}$.

A experiência de migração da cultura camponesa na Polônia para o clima industrial da crescente metrópole de Chicago, nos EUA, está forçando uma mudança de perspectiva e requer uma constante reflexão sobre a própria situação social (FISCHERROSENTHAL, 1995). Isso não era necessário nas colônias brasileiras de migrantes, lembradas acima, porque permitiam o uso da língua nativa e as principais técnicas culturais do país de origem na nova situação de vida, e por causa da proximidade social - a família, os parentes, a comunidade religiosa - o mesmo permaneceu. Isso significa, que neste caso, os emigrantes de Hunsrück não encontram uma Modernidade Organizada.

As migrações trabalhistas do século $\mathrm{XX}$, por outro lado, baseiam-se em diferenças de modernização e tornam as sociedades mais modernas, neste caso em primeiro lugar os EUA, em sociedades de acolhimento (APITZSCH, 1999). O Pull-Effekt - efeito de atração - da migração foi grande. 
Após a Segunda Guerra Mundial, a migração laboral também ocorre entre os países do sul e do norte da Europa. Quando, por exemplo, italianos, espanhóis, portugueses, iugoslavos, e mais tarde turcos vieram para a Alemanha Ocidental, Holanda ou Suécia, esta não foi, de modo algum, uma decisão de migração. O esquema biográfico do programa de ação dos migrantes foi o ganho rápido de recursos (para a construção de uma casa, a compra de um pequeno negócio ou o início de uma família) e o retorno mais rápido possível ao país de origem (DAUSIEN; MECHERIL, 2006).

Normalmente, esses trabalhadores migrantes na Alemanha são chamados de Gastarbeiter - trabalhadores convidados. Eram procurados como mão de obra necessária, por um período administrável. Como parte viva da sociedade, eles não eram destinados e reconhecidos. Já em 1965, o escritor suíço Max Frisch, afirma: "Wir riefen Arbeitskräfte, und es kamen Menschen" ["Nós chamamos mão de obra e vieram pessoas"] (FRISCH, 1965).

Ninguém está preparado para ficar muito mais tempo do que o planejado, e então, no mais tardar após a proibição do recrutamento em 1973, esposas e famílias são buscadas e passam a envolver-se no projeto Ganhar Dinheiro. A ideia de retorno não é de forma alguma abandonada, mas vai se tornando cada vez mais irrealista. Mais afetada é a segunda geração - crianças, que nasceram em sua maioria na sociedade que recebeu seus pais como migrantes, mas ainda sendo socializadas no contexto da sociedade de origem (APITZSCH, 1990).

As sociedades anfitriãs mais ricas respondem aos múltiplos desafios com um nacionalismo metodológico, como o sociólogo alemão Ulrich Beck denominou este processo de assimilação social (BECK; GRANDE, 1997; 2010; WIMMER; SCHILLER, 2003). Eles examinam a situação dos trabalhadores migrantes e suas famílias exclusivamente sob a perspectiva do país de chegada e exigem assimilação acrítica para forçar a integração.

Os resultados são, como sabemos hoje, altamente problemáticos e contraproducentes - também, e especialmente, porque os migrantes são percebidos exclusivamente sob o contexto de uma assimilação deficiente (APITZSCH, 1999). Quais recursos eles trazem consigo e como esses recursos poderiam capacitar a sociedade anfitriã permanecem fora da discussão.

A importância da conexão entre migração e biografia é altamente problemática. O nacionalismo metodológico da pesquisa sobre migração ${ }^{\mathrm{iv}}$ obscurece a visão de pessoas concretas e ignora a estreita relação entre migração e biografia. Ele se concentra em 
políticas de estado que estão começando a desenvolver um sutil mecanismo de defesa e dependem implacavelmente de padrões normativos de comportamento que se opõem irremediavelmente aos migrantes através de uma espécie de cultura orientadora ${ }^{v}$.

\section{Migrações transnacionais como um sintoma da pós-modernidade}

Basicamente, um olhar mais atento à migração laboral, especialmente os da segunda e terceira geração, já toca no tema da transmigração (APITZSCH, 2014). Um exemplo concreto: - ambos, pai e mãe de uma família migrante, trabalham tão intensamente para o planejado projeto de mérito, que é tomada a decisão de deixar as crianças com os avós em seu país natal. Muitas vezes, essa decisão leva a um movimento pendular entre os países, o que pode prejudicar o percurso educacional das crianças. Ocasionalmente, entretanto, há também avanços educacionais fascinantes ${ }^{\mathrm{vi}}$, porque a mudança entre locais de diferentes sociedades nacionais não é uma exceção temporária, mas sob a perspectiva biográfica das crianças afetadas é um estado normal e implica em uma nova competência altamente interessante (APITZSCH; SIOUTI, 2013).

No entanto, o conceito de transnacionalização tenta captar os mundos sociais emergentes não somente a partir da perspectiva do país de chegada, mas do ponto de vista dos sujeitos atuantes envolvidos (SIOUTI, 2018; LEVITT; SCHILLER, 2004). Tais espaços transnacionais são onipresentes em todo o mundo (PRIES, 2000): entre os EUA e o México ${ }^{\text {vii }}$, entre Singapura e as Filipinas, e também entre a Alemanha e algumas sociedades da Europa Oriental, como a Polônia, a Romênia, a Bulgária ou a Ucrânia ${ }^{\text {viii }}$.

O que emerge na experiência desses espaços são novas identidades transnacionais que superam o modelo binário de emigrantes e imigrantes, incluindo fatores de push e pull (SIOUTI, 2013). Como mostram os recentes estudos migratórios nos EUA, surgem estruturas de redes transnacionais que também abordam as mudanças políticas e econômicas globais (HEIN; KOHLMORGEN; BARTSCH, 2007). Basicamente, tais estruturas de rede substituem analiticamente a noção de globalização, que aborda principalmente os processos econômicos sem sujeitos intencionalmente atuantes. Isto quer dizer, que a extensão do conceito de migração para espaços transnacionais também muda os sujeitos participantes e suas biografias. Isso leva a uma qualidade que a socióloga e cientista política alemã Ursula Apitzsch chamou de conhecimento biográfico transnacional (2014, p. 22). Essa qualidade altera o Subjektcod - código temático -, por assim dizer: - a identidade biográfica pós-moderna não está mais 
ligada a uma única identidade cultural, mas prospera na mudança inteligente e flexível das identidades culturais (RECKWITZ, 2006, p. 482s.). Surge, pelo menos, o potencial das identidades cosmopolitas que poderiam formar a base de uma sociedade civil mundial.

Os conceitos pós-modernos de migração tornam, desta forma, visíveis os recursos estratégicos dos temas e conceitos atuantes. Eles se opõem justamente ao nacionalismo metodológico da fase de migração de trabalhadores (WIMMER; SCHILLER, 2003). Mas eles também estão em perigo. Espaços de migração transnacional estão continuamente se expandindo e esmaecendo com os fluxos globais de refugiados. Atualmente, o Conselho de Refugiados da ONU registra oficialmente mais de 68 milhões de refugiados em todo o mundo. Eles também seguem os espaços transnacionais, por exemplo, entre a África e a Europa. E somente se surgirem situações para eles em que possam atuar novamente de forma autônoma e ativamente como sujeitos, em vez de serem instrumentalizados por contrabandistas criminosos e brutalmente rejeitados por potenciais sociedades de acolhimento, uma síntese entre migração e biografia é sustentável.

Fica como uma conclusão: a relação entre migração e (auto)biografia é extremamente complexa, com aspectos históricos, filosóficos, éticos, econômicos, políticos e metodológicos. Uma solução para todos os problemas inerentes ao relacionamento dependeria de políticas humanas e civis em todo o mundo. Lamentavelmente, a situação atual do mundo apresenta pouca esperança quanto a este aspecto.

\section{Referências}

ALHEIT, Peter. 'Subject figurations' within Modernity: the change of autobiographical formats. In: FORMENTI, Laura; HORSDAL, Marianne; WEST, Linden (eds.). Embodied Narratives. Connecting stories, bodies, cultures and ecologies. Viborg: University Press of Southern Denmark, 2014. p. 107-128.

ALHEIT, Peter. Biograficidade. Natal: Editora da UFRN, 2019a. (No prelo).

ALHEIT, Peter. Codierungen des Subjektiven. Methodologische und historische Reflexionen zur Verknüpfung von Biographie und Diskurs. In: ALHEIT, Peter et al. (eds.). Reflexive Forschungspraxis. Zur Analyse von Biographien in ihren gesellschaftlichen Kontexten. Frankfurt am Main, New York: Campus (forthcoming), 2019b.

ALHEIT, Peter; BRANDT, Morten. Autobiographie und ästhetische Erfahrung. Entstehung und Wandel des Selbst in der Moderne. Frankfurt am Main, New York: Campus, 2006. 
ALHEIT, Peter; DAUSIEN, Bettina. Biographie. In: SANDKÜHLER, Hans Jörg (ed.). Europäische Enzyklopädie zu Philosophie und Wissenschaften. Hamburg: Meiner, 1990. v. 1. p. 405-418.

ALHEIT, Peter; SCHÖMER, Frank. Der Aufsteiger. Autobiographische Zeugnisse zu einem Prototypen der Moderne von 1800 bis heute. Frankfurt am Main, New York: Campus, 2009.

APITZSCH, Ursula; SIOUTI, Irini. Die Entstehung transnationaler Familienbiographien in Europa. Transnationales biographisches Wissen als zentrales Schlüsselkonzept zum Verständnis von transnationalen mehrgenerationalen Migrationsprozessen. In: BENDER, Desirée et al. (eds.). Transnationales Wissen und Soziale Arbeit. Weinheim: Juventa, 2013. p. 144-158.

APITZSCH,Ursula. Migration und Biographie. Zur Konstitution des Interkulturellen in den Bildungsgängen junger Erwachsener der zweiten Migrantegeneration. Habilitationsschrift Universität Bremen, 1990

APITZSCH, Ursula. Migration und Traditionsbildung. Opladen: Westdeutscher Verlag, 1999.

APITZSCH, Ursula. Transnationale Familienkooperation. In: GEISEN, Thomas et al. (eds.). Migration, Familie und Gesellschaft. Wiesbaden: Springer, 2014. p. 13-26.

AGUSTINUS, Aurelius. Bekenntnisse. Leipzig: Reclam, 1888

BADE, Klaus J. et al. (eds.). Enzyklopädie Migration in Europa: Vom 17. Jahrhundert bis zur Gegenwart. Paderborn: Ferdinand Schöningh, 2007.

BATTISTINI, Lorenzo. Autobiografia e Rinascimento: il 'clamoroso' caso di Francesco Guicciardini. In: BATTISTINI, Lorenzo et al. (eds.). La letteratura italiana e le arti. Atti del XX Congresso del Associazione degli Italianisti (ADI). Roma: Adi editore, 2016. p. $1-8$.

BECK, Ulrich; GRANDE, Edgar. Was ist Globalisierung? Irrtümer des Globalismus Antworten auf Globalisierung. Frankfurt am Main: Suhrkamp, 1997.

BECK, Ulrich; GRANDE, Edgar. Jenseits des methodologischen Nationalismus. Außereuropäische und europäische Variationen der Zweiten Moderne. Soziale Welt, 61, 2010, p. 187-216.

BRACHTENDORF, Johannes. Augustins "Confessiones ". Darmstadt: Wissenschaftliche Buchgesellschaft, 2005.

BRÄKER, Ulrich. Lebensgeschichte und Natürliche Ebenteuer des Armen Mannes im Tockenburg. Stuttgart: Reclam, 1993. (Original: 1789).

BURKE, Peter. The Historical Anthropology of Early Modern Italy. Cambridge: Cambridge University Press, 1987.

DAUSIEN, Bettina; MECHERIL, Paul. Normalität und Biographie. Anmerkungen aus migrationswissenschaftlicher Sicht. In: BUKOW, Wolf-Dietrich et al. (eds.). Biographische Konstruktionen im multikulturellen Bildungsprozess. Individuelle Standortsicherung im globalisierten Alltag. Wiesbaden: VS Verlag, 2006, p. 155-179.

DETERING, Hermann. $O$ du lieber Augustin. Falsche Bekenntnisse. Aschaffenburg: Alibri, 2014.

DICKIE, Maria Amélia Schmidt. Afetos e circunstâncias. Os Mucker e seu tempo. São Leopoldo: Oikos/Editora Unisinos, 2018; 
EVANS, James. Emigrants. Why the English Sailed to the New World. London: Orion Publishing Group, 2017.

FISCHER-ROSENTHAL, Wolfram. THOMAS, William I., ZNANIECKI, Florian. The Polish Peasant in Europe and America. In: UFLICK, Uwe Flick et al. (eds.). Handbuch Qualitative Sozialforschung: Grundlagen, Konzepte, Methoden und Anwendungen. Weinheim: Beltz Psychologie Verlagsunion, 1995. p. 115-118.

FRIES, James F.; CRAPO, L. M. Vitality and Aging. Implications of the Rectangular Curve. San Francisco: W.A. Freeman, 1981.

FRISCH, Max. Vorwort. In: SEILER, Alexander J. (ed.). Siamo Italiani - die italianer Gespräche mit italianischer Gastarbeitern. Zurich: E. V. Z. Verlag, 1965. p. 7-11.

HAHN, Alois. Biographie und Lebenslauf. In: BROSE, Hanns-Georg; HILDENBRAND, Bruno (eds.). Vom Ende des Individuums zur Individualität ohne Ende. Opladen: Leske/Budrich, 1988. Pp. 91-105.

HEIN, Wolfgang, KOHLMORGEN, Lars, BARTSCH, Sonja. Netzwerke und Governance. Transnationale Netzwerke als Grundlage emanzipatorischer Politik in der Weltgesellschaft? Peripherie. Zeitschrift für Politik und Ökonomie in der Dritten Welt, 105/106, 2007, p.8-34.

HELECK, Mechthild (ed.). Hildegard von Bingen. Das Buch vom Wirken Gottes. Liber divinorum operum. Erste vollständige Ausgabe. Augsburg: Pattloch, 1998.

IMHOF, Arthur. Die Lebenszeit. Vom aufgeschobenen Tod und von der Kunst des Lebens. München: C.H. Beck, 1988.

LEE, Everett S. A Theory of Migration. Demography. v. 3, n. 1. New York: Springer, 1966, p. 47-57.

LEVITT, Peggy; SCHILLER, Nina Glick. Transnational Perspectives on Migration: Conceptualizing Simuntaneity. International Migration Review, 38 (3), 2004, p. $1002-$ 1039.

MÜNKLER, Herfried. Der Dreißigjährige Krieg. Europäische Katastrophe, deutsches Trauma 1618-1648. Berlin: Rowohlt, 2017.

NOWAK, Martin A. Five Rules for the Evolution of Cooperation. Cambridge: Harvard Univrsity, 2006.

PRIES, Ludger, "Transmigranten" als ein Typ von Arbeitswanderern in pluri-lokalen sozialen Räumen. In: GOGOLIN, Ingrid; NAUCK, Bernhard (eds.). Migration, gesellschaftliche Differenzierung und Bildung. Opladen: Leske/Budrich, 2000, p. 415439.

RECKWITZ, Andreas. Das hybride Subjekt. Eine Theorie der Subjektkulturen von der bürgerlichen Moderne zur Postmoderne. Weilerswist: Velbrück Wissenschaft, 2006.

REGIONALGESCHICHTE.NET. Auswanderung nach Brasilien. Regionalgeschichte.net. Disponível em: <http://www.auswanderungrlp.de/auswanderung-nach-brasilien/19-jahrhundert/einleitung.html>. Acesso em 5 set. 2018.

SIOUTI, Irini. Transnationale Biographien. Eine biographieanalytische Studie über Transmigrationsprozesse bei der Nachfolgegeneration griechischer Arbeitsmigranten. Bielefeld: Transcript, 2013. 
SIOUTI, Irini. Migration und Biographie. In: LUTZ, Helma; SCHIEBEL, Martina; TUIDER, Elisabeth (eds.). Handbuch Biographieforschung. Wiesbaden: Springer, 2018. p. 223-232.

STEFFENSKY, Fulbert. Schwarzbrotspiritualität. Stuttgart: Radius, 2005.

THOMAS, William Isaac; ZNANIECKI, Florian. The Polish Peasant in Europe and America. 2. v. New York: Dover Publications, 1958 (Original 1918-1920).

WIMMER, Andreas; SCHILLER, Nina Glick. Methodological nationalism, the social sciences and the study of migration: An essay in historical epistemology. International Migration Review, 37 (3), 2003, p. 576-610.

Recebido: 23/03/2019

Aceito: $10 / 04 / 2019$

Publicado: 13/05/2019

\footnotetext{
* Traduzido do alemão por Dr. Jorge Luiz da Cunha, Universidade Federal de Santa Maria, Brasil. E-mail: jlcunha11@yahoo.com.br

ii Doutor em Filosofia da Religião e Doutor em Ciências Sociais. Professor na Georg-August-Universität Göttingen, Alemanha. E-mail: palheit@gwdg.de.

ii Este formato surpreendentemente precoce de uma autobiografia moderna é - especialmente por essa razão - colocada em questionamento pelo teólogo alemão Hermann Detering, em seu polêmico estudo $O$ du lieber Augustin. Falsche Bekenntnisse [Ó, querido Augustin. Falsas Confissões] (2014), e atribuída com razões bastante compreensíveis a Anselmo de Canterbury (1033-1109).

iii “A transformação da cultura do sujeito ocidental nas primeiras décadas do século XX está particularmente relacionada com as práticas de trabalho. Novas práticas de trabalho surgem no quadro dessa nova forma social que se desenvolve no final da modernidade burguesa: a organização moderna" (RECKWITZ, 2006, p. 336).

iv Uma disposição, aliás, que não caracteriza o estudo Chicago, de 1918-20, porque Florian Znaniecki, o co-autor, é um sociólogo polonês.

v Para um exame crítico do conceito arriscado de cultura dominante", veja Nowak (2006).

${ }^{v i}$ Apitzsch dá o exemplo persuasivo da estudante greco-alemã Athina, que habilmente evita uma carreira escolar deficiente na Alemanha, obtendo o diploma de ensino superior na Grécia antes de estudar na Alemanha (APITZSCH, 2014, p. 18).

vii Um espaço transnacional que Trump quer separar com a construção de um muro.

viii Por exemplo, nas áreas econômicas identificadas como Grau Bereichen - cinzentas -a, como cuidado geriátrico ou ocupações de limpeza.
} 